\title{
Receptive Fields of Retinal Bipolar Cells Are Mediated by Heterogeneous Synaptic Circuitry
}

\author{
Ai-Jun Zhang and Samuel M. Wu \\ Cullen Eye Institute, Baylor College of Medicine, Houston, Texas 77030
}

\begin{abstract}
Center-surround antagonistic receptive field (CSARF) organization is the basic synaptic circuit that serves as elementary building blocks for spatial information processing in the visual system. Cells with such receptive fields converge into higher-order visual neurons to form more complex receptive fields. Retinal bipolar cells (BCs) are the first neurons along the visual pathway that exhibit CSARF organization. $\mathrm{BCs}$ have been classified according to their response polarities and rod/cone inputs, and they project signals to target cells at different sublaminae of the inner plexiform layer. On the other hand, CSARFs of various types of BCs have been assumed be organized the same way. Here we examined center and surround responses of over 250 salamander BCs, and demonstrated that different types of BCs exhibit different patterns of dye coupling, receptive field center size, surround response strength, and conductance changes associated with center and surround responses. We show that $\mathrm{BC}$ receptive field center sizes varied with the degree of $\mathrm{BC}-\mathrm{BC}$ coupling, and that surround responses of different $\mathrm{BCs}$ are mediated by different combinations of five lateral synaptic pathways mediated by the horizontal cells and amacrine cells. The finding of heterogeneous receptive field circuitry fundamentally challenges the common assumption that CSARFs of different subtypes of visual neurons are mediated by the same synaptic pathways. BCs carrying different visual signals use different synaptic circuits to process spatial information, allowing shape and contrast computation be differentially modulated by various lighting and adaptation conditions.
\end{abstract}

Key words: receptive field; spatial information processing; crossover inhibition; heterogeneous pathways; feedback and feedforward synapses; electrical coupling

\section{Introduction}

Bipolar cells (BCs) are central neurons of the retina which carry light-elicited signals from photoreceptors and horizontal cells (HCs) in the outer retina to amacrine cells (ACs) and ganglion cells (GCs) in the inner retina (Dowling, 1987). BCs are the first neurons along the visual pathway that exhibit center-surround antagonistic receptive field (CSARF) organization, the basic synaptic circuit for encoding spatial information. Neurons with adjacent CSARFs converge into higher-order visual cells and form more complex receptive fields (Hubel and Wiesel, 1962). BCs may be on-center with off-surround [depolarizing BCs (DBCs)], or off-center with on-surround [hyperpolarizing BCs (HBCs)]. In addition to dividing into DBCs and $\mathrm{HBCs}$, $\mathrm{BCs}$ are further classified according to their rod/cone inputs: rod (or roddominated), cone (or cone-dominated), or mixed rod/cone BCs (Wu et al., 2000; Wassle, 2004). By using whole-cell voltage clamp technique in living retinal slices, we found in previous studies that BCs with different rod/cone inputs exhibit different axonal morphology [levels of axon terminal stratification in the inner plexi-

Received 0ct. 15, 2008; revised Dec. 8, 2008; accepted Dec. 14, 2008.

This work was supported by grants from the National Institutes of Health (EY 04446), National Institutes of Health Vision Core (EY 02520), the Retina Research Foundation (Houston), and the Research to Prevent Blindness, Inc. We thank Andrew Barrow, Cameron Cowan, and David Simon for critically reading this manuscript.

Correspondence should be addressed to Samuel M. Wu, Cullen Eye Institute, Baylor College of Medicine, One Baylor Plaza, NC-205, Houston, TX 77030. E-mail: swu@bcm.tmc.edu.

DOI:10.1523/JNEUROSCI.4984-08.2009

Copyright $\odot 2009$ Society for Neuroscience $\quad$ 0270-6474/09/290789-09\$15.00/0 form layer (IPL)] and different spontaneous and light-evoked responses (Wu et al., 2000; Pang et al., 2004). Because of geometric limitations of the retinal slice preparation, we could not study receptive field properties of various types of BCs, and thus many important knowledge gaps remained unfilled. For example, it was not clear whether the receptive field center size of different types of $\mathrm{BCs}$ differ, and why the receptive field centers of most BCs were much larger than their dendritic fields (Borges and Wilson, 1987; Hare and Owen, 1990). Additionally, it was uncertain whether $\mathrm{DBCs} / \mathrm{HBCs}$ with different rod/cone inputs generate surround responses through the same synaptic pathways.

In this study, we fill these knowledge gaps by systematically investigating detailed center-surround receptive field properties of a large number of BCs in the flat-mounted tiger salamander retina. We examine center and surround response properties, degree of dye coupling, and membrane resistance changes associated with the center and surround responses in over 250 BCs. Our study renders a comprehensive description of how centersurround receptive fields of various types of BCs are organized, and provides evidence that challenges the common assumption that receptive fields of subtypes of visual neurons are mediated by same synaptic pathways.

\section{Materials and Methods}

Flat-mounted, isolated retinas of larval tiger salamanders (Ambystoma tigrinum) purchased from Charles E. Sullivan, $\mathrm{CO}$ and KON's Scientific Company were used in this study. Animals were handled in accordance with the policies on treatment of laboratory animals of Baylor College of 
Medicine and the National Institutes of Health. Detailed experimental procedures were described in previous publications (Yang and Wu, 1989; Zhang et al., 2006). Before an experiment, the animal was dark-adapted for at least $2 \mathrm{~h}$ and then decapitated and dissected under infrared illumination with a dual-unit Nitemare (BE Meyers). Oxygenated Ringer's solution was introduced to the superfusion chamber at a rate of $\sim 5$ $\mathrm{ml} / \mathrm{min}$, so that the retina was immersed totally under solution. The control Ringer's solution contained $108 \mathrm{~mm} \mathrm{NaCl}, 2.5 \mathrm{~mm} \mathrm{KCl}, 1.2 \mathrm{~mm}$ $\mathrm{MgCl}_{2}, 2 \mathrm{~mm} \mathrm{CaCl}_{2}$, and $5 \mathrm{~mm}$ HEPES (adjusted at $\mathrm{pH}$ 7.7). Bath applied pharmacological agents were dissolved in Ringer's solution, and $\mathrm{pH}$ was readjusted after agents were dissolved.

Intracellular recordings were made with micropipettes drawn out on a modified Livingstone puller or Sutter microelectrode puller with singlebarrel $\omega$ dot tubing. The pipettes were filled with $2 \mathrm{~m}$ potassium acetate and have resistance, measured in Ringer's solution of 100-600 M $\Omega$. Bipolar cells, amacrine cells, and ganglion cells were recorded with a microelectrode amplifier (MEZ-8300, Nihon Kohden). For conductance measurements, trains of constant current steps of given amplitude and duration were generated by the internal circuit of the amplifier, and voltage changes were monitored by the MEZ-8300 system. For cell morphology and dye coupling studies, microelectrode tips were filled with $3 \%$ Neurobiotin and 1\% Lucifer yellow in $50 \mathrm{~mm}$ Tris and backfilled with $3 \mathrm{~m}$ lithium chloride. After physiological experiments, dyes were injected with positive and negative currents (1-5 nA, $3 \mathrm{~Hz}, 30 \mathrm{~min})$. Then the tissues were fixed with $4 \%$ paraformaldehyde for $2 \mathrm{~h}$ and were subsequently immunolabeled with streptavidin conjugated Cy-3. Cell morphology and patterns of dye coupling were visualized with a confocal microscope (Zeiss 510). Images were acquired by using a $\times 25$ or $\times 40$ oil-immersion objective (numerical aperture $=0.75$ ), the $458 \mathrm{~nm}$ excitation line of an argon laser, and a long-pass $505 \mathrm{~nm}$ emission filter. Consecutive optical sections were stacked into a single image using the Zeiss LSM-PC software, and the stacked images were further processed in Adobe Photoshop 6.0 to improve the contrast.

A new computerized, dual-beam light stimulator with an automated projector head, was constructed for experiments that require center and surround light stimuli in flat-mounted retinas. Both light beams pass through interference filters, neutral density filters and apertures of various configurations mounted on motorized wheels controlled by the computer. The receptive field of a given cell was mapped by a moving light bar (100 $\mu \mathrm{m}$ wide) through the automated projector head in two orthogonal directions, and the cell's receptive field center was determined by the intersecting point of the maximum responses to the light bar in the two directions. The center light spot (with various diameters) and a concentric surround light annulus (with various inner and outer diameters) were projected to the retina. The receptive field center diameter (RFCD) is determined as the mean distance that the light bar needs to travel from eliciting $5 \%$ of the maximum center response in one direction of the center location to eliciting $5 \%$ of the maximum response in the opposite direction. The intensity of unattenuated $500 \mathrm{~nm}$ light (log $\mathrm{I}=0)$ is $2.05 \times 10^{7}$ photons $/ \mu \mathrm{m}^{2} / \mathrm{s}$.

\section{Results \\ Morphology, patterns of dye coupling and light responses of six types of bipolar cells}

$\mathrm{BCs}$ in the flat-mounted tiger salamander retina were recorded with microelectrodes. When filled with Lucifer yellow and/or neurobiotin, they were identified morphologically by their somas located in the inner nuclear layer (INL) or in the proximal margin of the outer nuclear layer (ONL) (displaced BCs) (Maple et al., 2004), dendrites in the outer plexiform layer (OPL), and an axon extended to the IPL (Pang et al., 2004). All BCs exhibited centersurround antagonistic receptive fields. One hundred eighty-one cells responded to a center light spot with membrane hyperpolarization, and to a surround light annulus with depolarization, these are the HBCs. Seventy-three cells responded to center light with depolarization and surround light with hyperpolarization, and they are the DBCs.
Figure $1 a$ shows fluorescent micrographs of a neurobiotinfilled, rod-dominated $\mathrm{HBC}\left(\mathrm{HBC}_{\mathrm{R}}\right.$, column 1$)$, a mixed rod/cone HBC $\left(\mathrm{HBC}_{\mathrm{M}}\right.$, column 2$)$, a cone-dominated $\mathrm{HBC}\left(\mathrm{HBC}_{\mathrm{C}}\right.$, column 3), a cone-dominated DBC ( $\mathrm{DBC}_{\mathrm{C}}$, column 4), a mixed $\mathrm{rod} /$ cone $\mathrm{DBC}\left(\mathrm{DBC}_{\mathrm{M}}\right.$, column 5), and a rod-dominated $\mathrm{DBC}$ $\left(\mathrm{DBC}_{\mathrm{R}}\right.$, column 6) viewed with a confocal microscope at the outer INL/OPL level (Fig. $1 a_{i}$ ), the IPL level (Fig. $1 a_{i i}$ ), and with $z$-axis rotation (Fig. $1 a_{i i i}$ ). We list these BCs in this order based on the levels of their axon terminal stratification in the IPL [from distal margin (0\%) to proximal margin (100\%) of the IPL] (Fig. $1 a_{i i i}$ ) (Pang et al., 2004). Figure $1 b_{i}$ shows BC voltage responses to 500 and $700 \mathrm{~nm}$ light steps of various intensities, and Figure $1 b_{i i}$ illustrates response-intensity $(\mathrm{V}-\mathrm{L} \operatorname{Lg} \mathrm{I})$ curves of the responses to 500 and $700 \mathrm{~nm}$ lights. We have shown that HBCs or DBCs in the salamander retina can be classified according to their relative $\mathrm{rod} /$ cone inputs by the spectral difference method (Yang and $\mathrm{Wu}, 1990$; Pang et al., 2004). The spectral difference of a cell $(\Delta \mathrm{S})$ is defined as $S_{700}-S_{500}$ (in which $S_{700}$ and $S_{500}$ are intensities of 700 and $500 \mathrm{~nm}$ light-eliciting responses, respectively, of the same amplitude). Because $\Delta S$ for the rods is $\sim 3.4$ and that for the cones is $\sim 0.1$ in the salamander retina (Yang and $\mathrm{Wu}, 1990$ ), we defined BCs with $\Delta \mathrm{S}>2.0$ rod-dominated BCs, BCs with $\Delta \mathrm{S}<1.0$ cone-dominated BCs, and BC with $1.0<\Delta S<2.0$ mixed rod/ cone BCs. The $\Delta$ Ss of the six BCs in Figure 1 are 2.13, 1.51, 0.30, $0.57,1.45$, and 2.25 , suggesting that they are $\mathrm{HBC}_{\mathrm{R}}, \mathrm{HBC}_{\mathrm{M}}$, $\mathrm{HBC}_{\mathrm{C}}, \mathrm{DBC}_{\mathrm{C}}, \mathrm{HBC}_{\mathrm{M}}$, and $\mathrm{HBC}_{\mathrm{R}}$, respectively. These are consistent with our voltage clamp data from retinal slices that BCs with axon terminals stratified near the IPL distal margin are $\mathrm{HBC}_{\mathrm{R}} \mathrm{S}$, those with axon terminals stratified progressively toward the distal IPL margin are (in progressive order) $\mathrm{HBC}_{\mathrm{M}}, \mathrm{HBC}_{\mathrm{C}}, \mathrm{DBC}_{\mathrm{C}}$, $\mathrm{DBC}_{\mathrm{M}}$, and $\mathrm{DBC}_{\mathrm{R}}$ (Pang et al., 2004). We performed these experiments on $173 \mathrm{BCs}$ and $\Delta S$ values for each cell were correlated with the levels of axon terminal stratification in the IPL as revealed by Lucifer yellow or neurobiotin fluorescence. The total cell numbers for the six BC types are given in Table 1, column 2.

With neurobiotin injections, we found that the six types of BCs exhibit different patterns of dye coupling. The numbers of dye-coupled somas $\left(\mathrm{N}_{\mathrm{DC}}, 30 \mathrm{~min}\right.$ dye injection time for all cells) in Figure $1 a_{i}$ are $10,5,2,8,3$, and 1 , respectively, for the $\mathrm{HBC}_{\mathrm{R}}$, $\mathrm{HBC}_{\mathrm{M}}, \mathrm{HBC}_{\mathrm{C}}, \mathrm{DBC}_{\mathrm{C}}, \mathrm{DBC}_{\mathrm{M}}$, and $\mathrm{DBC}_{\mathrm{R}}$. These numbers are consistent with $\mathrm{N}_{\mathrm{DC}}$ within each type (Table 1, column 3). In each $\mathrm{BC}$ type, the injected cell body and other labeled somas are located at the same level of the INL, and their axon terminals stratified at about the same level in the IPL, indicating the dyecoupled cells are likely to be the same type. The only exception to this rule is the $\mathrm{DBC}_{\mathrm{C}} \mathrm{s}$, around which we often found labeled somas that did not bear axons projecting to the IPL. In Figure $1 a_{i}$, column 4, for example, three of the eight labeled somas (arrowheads) were horizontal cells. This is consistent with results from previous studies that some wide field horizontal cells (B-type) in the salamander and mammalian retinas are dye coupled with a population of bipolar cells with axon terminals stratified in IPL sublamina B (Zhang et al., 2006).

\section{Receptive field center sizes of various types of bipolar cells}

Assuming that the extent of dye coupling correlates with the strength of electrical coupling (Zhang et al., 2006), then the results in Figure $1 a_{i}-a_{i i i}$ suggest that $\mathrm{HBC}_{\mathrm{R}} \mathrm{s}$ are strongly coupled with one another, $\mathrm{DBC}_{\mathrm{R}} \mathrm{s}$ are not coupled, and $\mathrm{HBC}_{\mathrm{M}} \mathrm{s}, \mathrm{HBC}_{\mathrm{C}} \mathrm{s}$, $\mathrm{DBC}_{\mathrm{C}} \mathrm{s}$, and $\mathrm{DBC}_{\mathrm{M}} \mathrm{s}$ are intermediately coupled. This kind of electrical coupling (among the same cell types) is known to increase the receptive field size of the horizontal cells (Zhang et al., 2006) and other retinal neurons (Bloomfield and Xin, 1997), and 

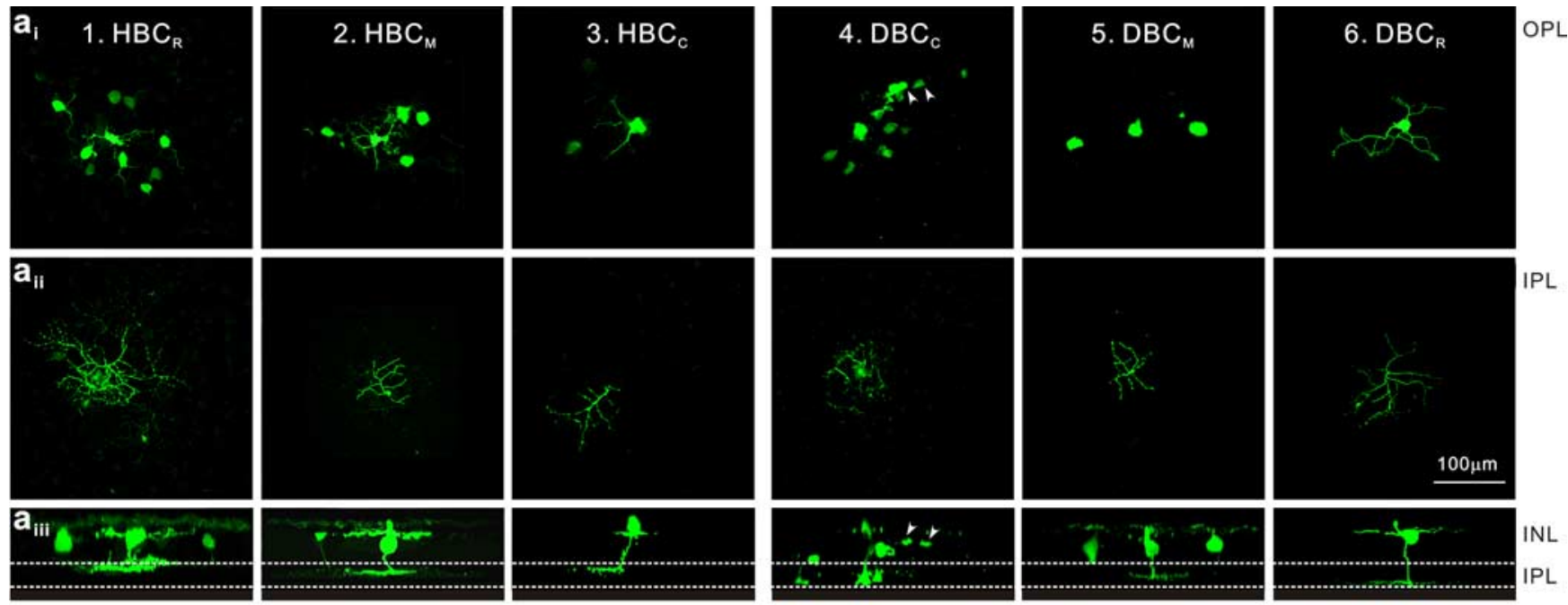

INL
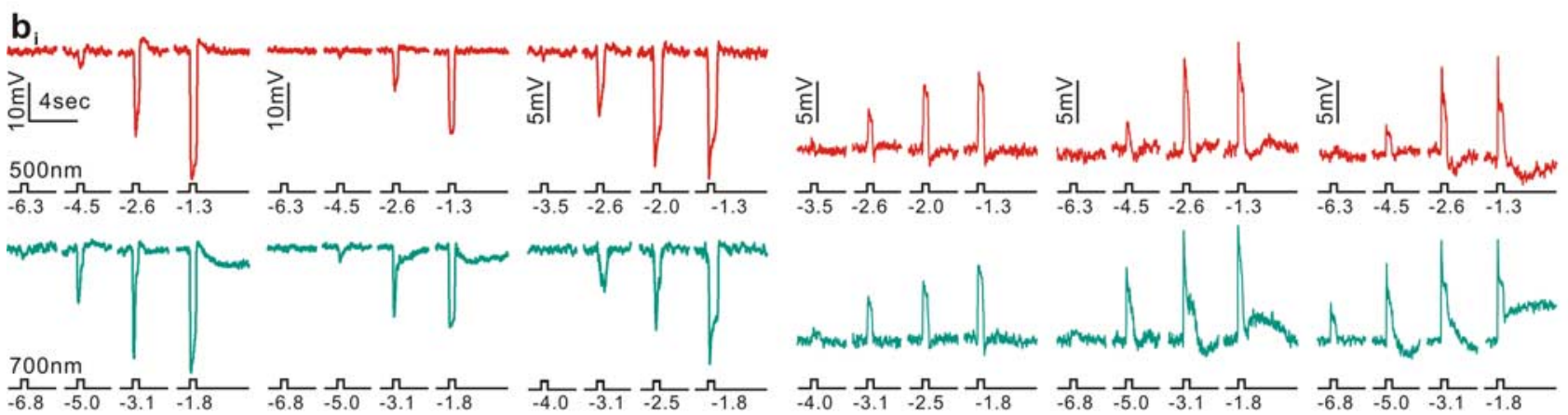

b $_{\text {ii }}$
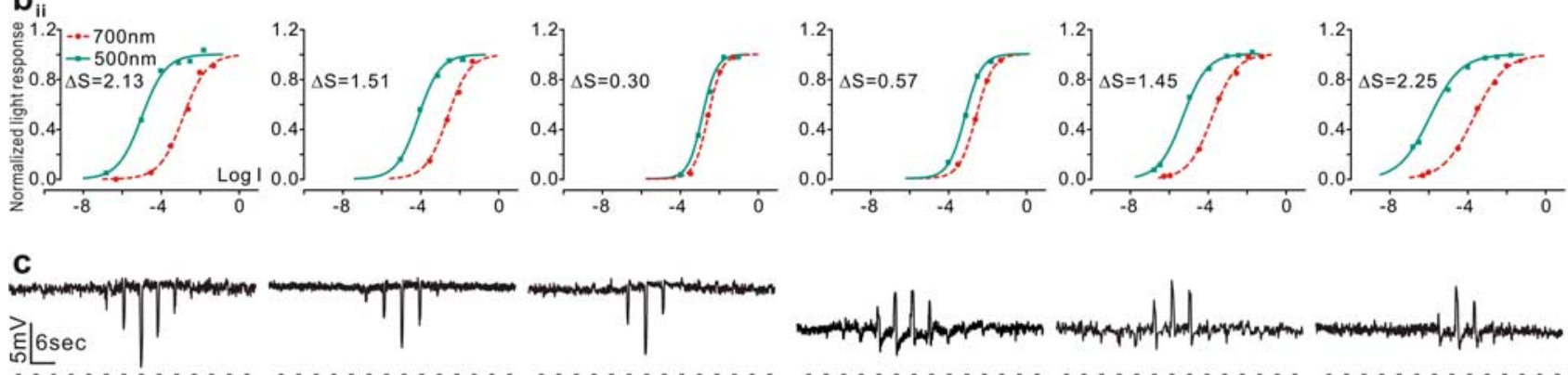

Light Steps( $120 \mu \mathrm{m}$ apart)
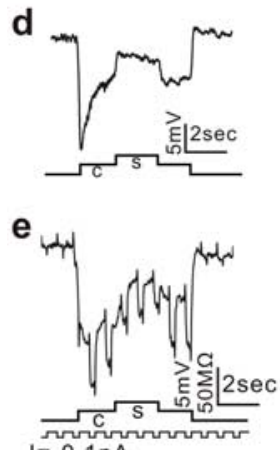
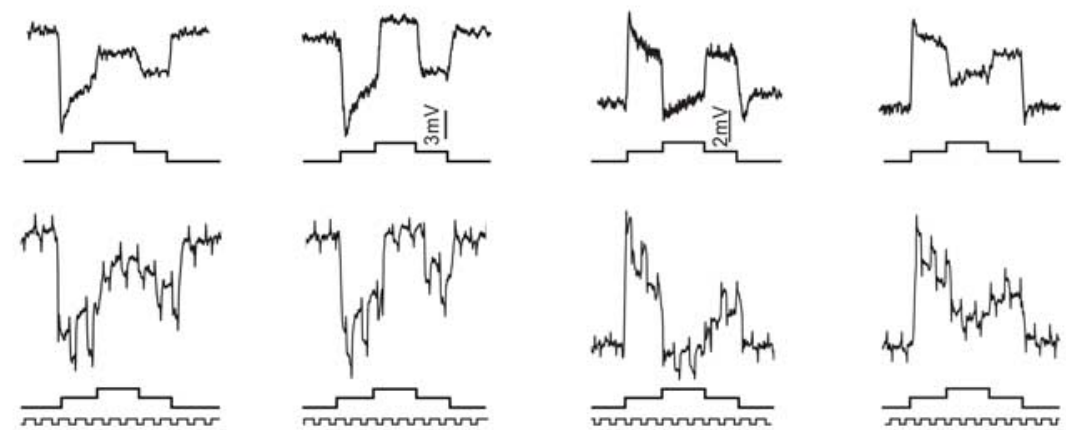
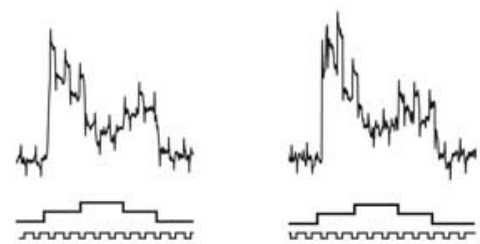

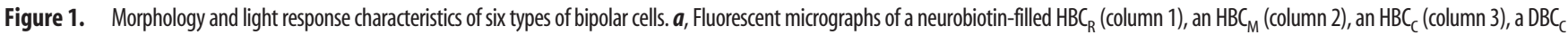

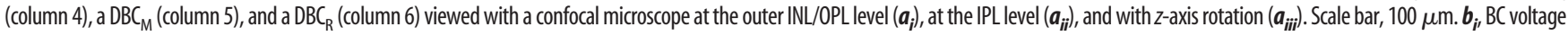
responses to 500 and $700 \mathrm{~nm}$ light steps of various intensities. $\boldsymbol{b}_{i j}$, Response-intensity (V-Log I) curves of the responses to 500 and $700 \mathrm{~nm}$ lights. $\Delta S$ (spectral difference) of the six BCs are 2.13, 1.51,0.30,0.57, 1.45 , and 2.25. $\boldsymbol{c}$, Measurements of BC RFCDs by recording voltage responses to a 100 - $\mu \mathrm{m}$-wide light bar moving stepwise (with $120 \mu \mathrm{m}$ step increments) across the receptive field. $\boldsymbol{d}$, Voltage responses of the six types of BCs elicited by a center light spot $(300 \mu \mathrm{m})$ and a surround light annulus (700 $\mu$ m inner diameter, $2000 \mu$ m outer diameter). The surround light annulus was of the same intensity $(700 \mathrm{~nm},-2)$ for all 6 cells whereas the intensity of the center light spot was adjusted so that itallowed the annulus to produce the maximum response.e, Voltage responses of the sixtypes of BCs elicited by a center light spot and a surround light annulus (same as in $\boldsymbol{d}$ ), and by a train of $-0.1 \mathrm{nA} / 200 \mathrm{~ms}$ current pulses passed into the cell by the recording microelectrode through a bridge circuit. 
Table 1. Receptive field properties of BCs

\begin{tabular}{|c|c|c|c|c|}
\hline$\overline{\mathrm{BCS}}$ & $\Delta S(n)$ & $\mathrm{N}_{\mathrm{DC}}$ range $(\mathrm{n})$ & $\operatorname{RFCD}(\mu \mathrm{m})$ & $S /\left(C_{t}-C_{s}\right)(n)$ \\
\hline$H B C_{R}$ & $\Delta S>2.0(32)$ & $7-12$ (19) & $528.50 \pm 84.05(23)$ & $0.23 \pm 0.19(15)$ \\
\hline $\mathrm{HBC}_{\mathrm{M}}^{\mathrm{n}}$ & $1<\Delta S<2$ & $3-6(24)$ & $396.89 \pm 55.80(47)$ & $0.73 \pm 0.43(26)$ \\
\hline $\mathrm{HBC}_{\mathrm{c}}$ & $\Delta S<1.0(27)$ & $2-3(20)$ & $353.82 \pm 25.24(22)$ & $0.96 \pm 0.30(21)$ \\
\hline $\mathrm{DBC}_{\mathrm{R}}$ & $\Delta S<1.0(20)$ & $2-6(10)$ & $357.67 \pm 22.03(14)$ & $1.15 \pm 0.21(9)$ \\
\hline $\mathrm{DBC}_{\mathrm{M}}$ & $1<\Delta S<2(26)$ & $1-3(11)$ & $334.00 \pm 23.73(18)$ & $0.97 \pm 0.18(13)$ \\
\hline $\mathrm{DBC}_{\mathrm{c}}$ & $\Delta S>2.0(13)$ & $1(10)$ & $276.36 \pm 24.51(10)$ & $0.62 \pm 0.23(7)$ \\
\hline
\end{tabular}

Values are the average $\pm S D$. Statistics of spectral difference $(\Delta S)$, number of dye-coupled cells (with 30-min neurobiotin injection) $\left(N_{D C}\right)$, receptive field diameter (RFCD), and relative surround response strength $\left[S /\left(C_{t}-C_{S}\right)\right]$ of various types of $B C s$ are listed.

thus it should affect the receptive field center size of BCs. We therefore examined the receptive field center diameter of each type of $\mathrm{BCs}$ by recording voltage responses to a $100 \mu \mathrm{m}$-wide light bar moving stepwise (with $120 \mu \mathrm{m}$ step increments) across the receptive field (Fig. 1c). The receptive field center diameters (RFCDs) (see Materials and Methods) of the six BCs in Figure 1 are $620,451,383,372,325$, and $263 \mu \mathrm{m}$, respectively. The average $( \pm \mathrm{SD})$ RFCDs of the six types of BCs (a total of 134) are listed in Table 1, column 4; these correlate very well with the numbers of dye-coupled BCs $\left(\mathrm{N}_{\mathrm{DC}}\right)$ listed in Table 1, column 3. These results indicate that the variation in $\mathrm{BC}$ receptive field center size is mediated at least partially by electrical coupling among BCs of the same kind.

Distributions of RFCD of 92 HBCs (filled circles) and 42 DBCs (open triangles) as function of relative rod/cone inputs (spectral difference $\Delta \mathrm{S}$ ) are shown in Figure $2 a$. Straight lines are linear regressions of the data points with slopes of $96.89 \mu \mathrm{m} / \mathrm{log}$ unit $\Delta \mathrm{S}$ for the HBCs (solid line), and $-44.56 \mu \mathrm{m} / \log$ unit $\Delta \mathrm{S}$ for the DBCs (dashed line), indicating that the receptive field center size of HBCs increases progressively with $\Delta S$ (larger RFCD for cells with more rod inputs), and that the receptive field size of DBCs decreases progressively with $\Delta \mathrm{S}$ (larger RFCD for cells with more cone inputs).

\section{Surround response strengths of bipolar cells}

We next investigated whether the strength of surround responses of $\mathrm{HBC}$ and $\mathrm{DBCs}$ vary with their rod/cone inputs. Figure $1 d$ are the voltage responses of the $\mathrm{HBC}_{\mathrm{R}}, \mathrm{HBC}_{\mathrm{M}}, \mathrm{HBC}_{\mathrm{C}}, \mathrm{DBC}_{\mathrm{C}}, \mathrm{DBC}_{\mathrm{M}}$, and $\mathrm{DBC}_{\mathrm{R}}$ elicited by a center light spot and a surround light annulus. The surround light annulus was of the same intensity for all six cells, whereas the intensity of the center light spot was adjusted so that it allowed the annulus to produce the maximum response, as light annulus elicits optimal surround response in amphibian BCs in the presence of center light of appropriate intensity (Skrzypek and Werblin, 1983). The relative surround response strength, $S /\left(C_{t}-C_{S}\right)\left(S, C_{t}\right.$, and $C_{S}$ are surround, transient center, and sustained rebound responses, respectively) (Fig. $2 b$, inset), of the six BCs in Figure 1 are $0.53,0.67,1.37,1.15,0.78$, and 0.26 . The average $( \pm S D) S /\left(C_{t}-C_{S}\right)$ values of the six types of BCs (a total of 91) are listed in Table 1, column 5. Figure $2 b$ shows the scatter plots of the relative surround response strength $\left[S /\left(C_{t}\right.\right.$ $-\mathrm{C}_{\mathrm{S}}$ )] of $62 \mathrm{HBCs}$ (filled circles) and 29 DBCs (open triangles) against relative rod/cone inputs (spectral difference $\Delta \mathrm{S}$ ). Linear regression lines of the data points render slopes of $-0.48 / \log$ unit $\Delta \mathrm{S}$ for the HBCs (solid line) and $-0.39 / \log$ unit $\Delta \mathrm{S}$ for the DBCs (dashed line), indicating that the relative surround response strength of both HBCs and DBCs decreases progressively with $\Delta \mathrm{S}$ (stronger surround responses for cells with more cone inputs).

\section{Membrane resistance changes accompanying center and surround bipolar cell responses}

To study the synaptic circuitry mediating center and surround inputs to BCs, we measured membrane resistance changes asso-
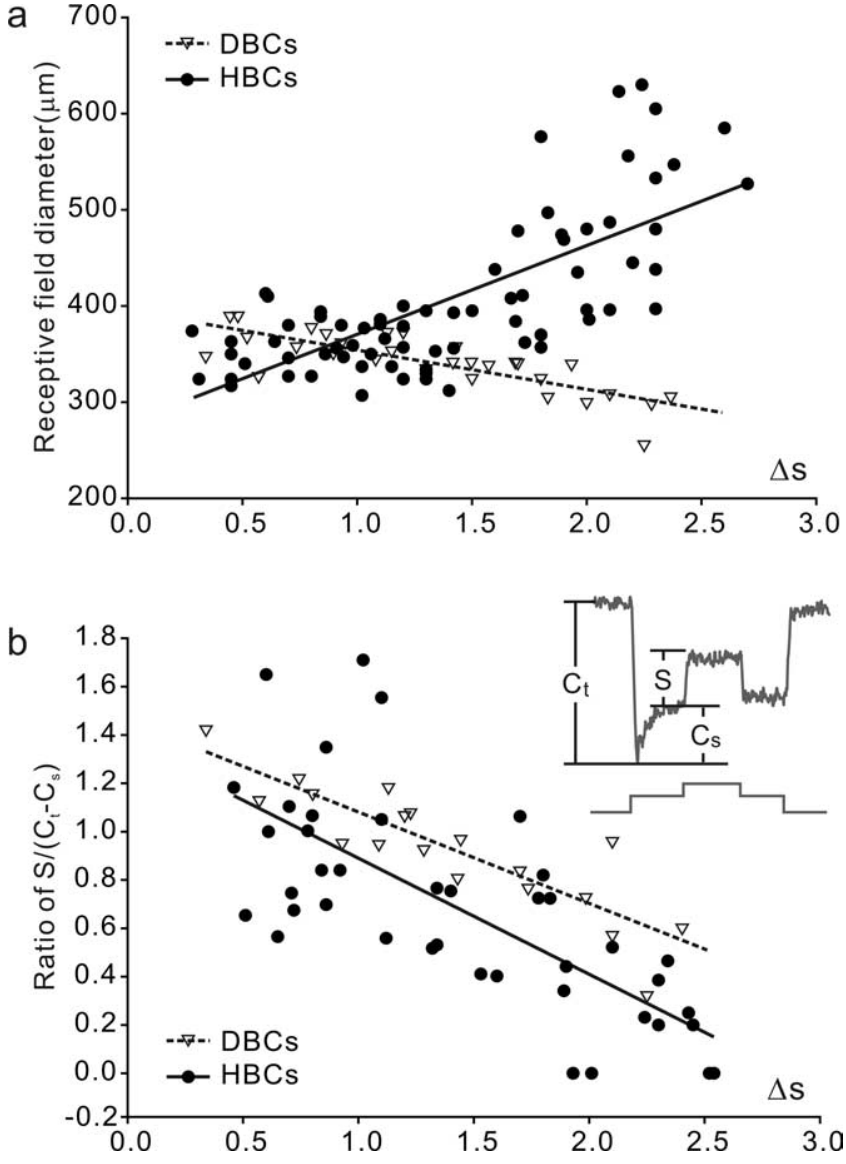

Figure 2. Scatter plots of receptive field properties of bipolar cells. $\boldsymbol{a}$, Scatter plots of receptive field diameter versus spectral difference $\Delta S$ of DBCS (open triangles and dashed line) and $H B C s$ (filled circles and solid line). Straight lines are linear regression lines of the data points. $\boldsymbol{b}$, Scatter plots of relative surround/center response ratio $\left[S /\left(C_{t}-C_{S}\right)\right]$ versus spectral difference $\triangle S$ of DBCs (open triangles and dashed line) and HBCs (filled circles and solid line). Straight lines are linear regression lines of the data points.

ciated with voltage responses to center and surround light in various types of $\mathrm{BCs}$. Figure 1e shows the voltage responses of a $\mathrm{HBC}_{\mathrm{R}}$, a $\mathrm{HBC}_{\mathrm{M}}$, a $\mathrm{HBC}_{\mathrm{C}}$, a $\mathrm{DBC}_{\mathrm{C}}$, a $\mathrm{DBC}_{\mathrm{M}}$, and a $\mathrm{DBC}_{\mathrm{R}}$ elicited by a center light spot and a surround light annulus, and by a train of $-0.1 \mathrm{nA} / 200 \mathrm{~ms}$ current pulses passed into the cell by the recording microelectrode through a bridge circuit. By balancing the bridge with measurable values of resistance before and after cell impalements, we estimated that the average input resistance of HBCs is $36.68 \pm 6.03 \mathrm{M} \Omega(n=46)$ and that for the DBCs is $52.70 \pm 11.68 \mathrm{M} \Omega(n=31)$. In addition to the difference in average input resistance between HBCs and DBCs, there is no obvious correlation between the resistance values and $\mathrm{HBC} / \mathrm{DBC}$ subtypes. It is also worthwhile to note that the accuracy of these resistance measurements may be affected by changes of micro- 
Table 2. Resistance measurements of BCs

\begin{tabular}{|c|c|c|c|c|}
\hline $\mathrm{BCs}$ & $\mathrm{R}_{\mathrm{m}}(\mathrm{M} \Omega)$ & $\Delta \mathrm{R}_{\text {Center }}(\mathrm{M} \Omega)$ & $\Delta \mathrm{R}_{\text {Surround }}(\mathrm{M} \Omega)$ & $\Delta \mathrm{R}_{\text {Surround }} \rightarrow \Delta \mathrm{R}_{\text {Center }}(\mathrm{M} \Omega)$ \\
\hline$H B C_{R}$ & $36.68 \pm 6.03(46)$ & $54.99 \pm 5.01(12)$ & $37.67 \pm 2.96(12)$ & $-17.32 \pm 2.63(12)$ \\
\hline $\mathrm{HBC}_{\mathrm{M}}$ & & $52.31 \pm 8.74(15)$ & $25.95 \pm 4.41(15)$ & $-26.36 \pm 6.21(15)$ \\
\hline $\mathrm{HBC}_{\mathrm{C}}$ & & $47.15 \pm 6.91(10)$ & $12.75 \pm 2.47(10)$ & $-34.40 \pm 4.80(10)$ \\
\hline $\mathrm{DBC}_{\mathrm{C}}$ & $52.70 \pm 11.68(31)$ & $-49.32 \pm 13.06(8)$ & $37.51 \pm 7.80(8)$ & $86.84 \pm 20.65(8)$ \\
\hline $\mathrm{DBC}_{\mathrm{M}}$ & & $-51.36 \pm 7.26(10)$ & $34.22 \pm 5.06(10)$ & $85.78 \pm 11.64(10)$ \\
\hline$D B C_{R}$ & & $-59.04 \pm 25.97(6)$ & $15.95 \pm 11.17(6)$ & $74.78 \pm 35.87(6)$ \\
\hline
\end{tabular}

Values are the average $\pm S D$ of input resistance measured in darkness $\left(R_{m}\right)$, resistance change accompanied by the center response $\left(\Delta R_{\text {center }}\right)$, resistance change accompanied by the surround response $\left(\Delta R_{\text {Surround }}\right)$, and the difference resistance change from center response to surround response $\left(\Delta R_{\text {surround }} \rightarrow \Delta R_{\text {center }}\right)$ of various types of $B C s$.

electrode tip resistance during cell impalement. On the other hand, the input resistance changes associated with center and surround voltage responses could be determined with reasonable accuracy by the voltage deflections induced by the given current pulses, because microelectrode tip resistance does not change during light stimulation. For HBCs, the center response was accompanied by a resistance increase (indicated by the downward voltage deflections), and the surround response accompanied by a resistance decrease (indicated by the decrease of downward voltage deflections). For DBCs, the center response was accompanied by a resistance decrease (indicated by the upward voltage deflections), and the surround response accompanied by a resistance increase (indicated by the decrease of upward voltage deflections or downward deflections). The average membrane resistance changes $(\Delta \mathrm{R})$ associated with center and surround responses of various types of HBCs $(n=37)$ and DBCs $(n=24)$ are listed in Table 2.

\section{Contribution of the $\mathrm{HC}-\mathrm{DBC}$ electrical synapses to $\mathrm{DBC}_{\mathrm{C}}$ surround responses}

Figure $1 a$ and our previous HC study (Zhang et al., 2006) suggest that $\mathrm{DBC}_{\mathrm{C}} \mathrm{s}$ are dye coupled with wide-field HCs (type B HC somas and axon terminals). This raises the possibility that the electrical synapses between wide-field $\mathrm{HCs}$ and $\mathrm{DBC}_{\mathrm{C}}$ s may contribute to the $\mathrm{DBC}_{\mathrm{C}}$ surround responses. To verify this surround pathway, we first eliminated the contribution of the HC-coneDBC feedback pathway to $\mathrm{DBC}_{\mathrm{C}}$ surround responses by bath applying L-AP4, which blocks the feedback surround signal by saturating the cone-DBC synapses. This is a crucial step for demonstrating $\mathrm{HC}-\mathrm{DBC}_{\mathrm{C}}$ electrical synapse contribution to the $\mathrm{DBC}_{\mathrm{C}}$ surround response because electrical synapse blockers have been shown to affect the HC-cone feedback synapses (Kamermans et al., 2001; Verweij et al., 2003). Figure $3 a$, middle trace, shows that the depolarizing center responses were abolished but the hyperpolarizing surround responses maintained (with slightly reduced amplitude) in the presence of $20 \mu \mathrm{M}$ L-AP4. We then added $100 \mu \mathrm{M}$ meclofenamic acid (MFA), a gap junction blocker (Pan et al., 2007), and found that it reversibly reduced the residual surround responses (Fig. $3 b$ ). We observed such MFA actions in 6 DBCs and all 6 cells were $\mathrm{DBC}_{\mathrm{C}} \mathrm{s}$ (based on their $\Delta S$ values and axon morphology) (Fig. $1 a, b)$. Hence it is likely that MFA suppresses $\mathrm{DBC}_{\mathrm{C}}$ surround responses by blocking the electrical synapses between the wide-field HCs and DB$\mathrm{C}_{\mathrm{C}} \mathrm{S}$, as shown in Figure $1 a$ and our previous HC study (Zhang et al., 2006). It is important to show that $100 \mu \mathrm{M}$ MFA did not affect the wide-field $\mathrm{HC}$ responses to spot and annulus light stimuli (Fig. $3 c, d$ ), and the receptive field size (Fig. $3 e$ ), and thus the MFA induced $\mathrm{DBC}_{\mathrm{C}}$ surround response suppression is caused by blockade of the $\mathrm{HC}-\mathrm{DBC}_{\mathrm{C}}$ gap junctions rather than by reducing $\mathrm{HC}$ responses to light annuli.

\section{Surround responses of various types of BCs are mediated by different combinations of lateral synaptic pathways}

The membrane resistance measurements in this study have several implications in BC surround responses. First, surround light responses of all HBCs are accompanied by a resistance decrease, and surround responses of all DBCs are accompanied by a resistance increase. This supports the idea that surround responses of all BCs are at least partially mediated by the HC-cone-HBC feedback circuitry (Baylor et al., 1971; Wu, 1992). Light annuli hyperpolarize $\mathrm{HCs}$ that depolarize cones in the $\mathrm{BC}$ receptive field center and increase glutamate release from these cones, which results in a depolarizing surround response accompanied by a resistance decrease in HBCs, and a hyperpolarizing surround response accompanied by a resistance increase in DBCs. Our observation that the surround responses are stronger for $\mathrm{HBC}$ and $\mathrm{DBCs}$ with more cone inputs (Fig. 2b) supports the idea that the HC-cone-BC feedback pathway plays an important role in mediating the surround responses of all six types of BCs, and the contribution of this pathway (pathway I) to HBCs and DBCs is illustrated in Figure 4.

The second implication is that in addition to the HC-coneDBC feedback pathway, DBC surround responses may be mediated by the HC-DBC feedforward chemical synapses (Fig. 4, pathway II) and/or OFF amacrine cell $\left(\mathrm{AC}_{\mathrm{OFF}}\right)$-DBC feedback synapses (Fig. 4, pathway IV) (Ichinose and Lukasiewicz, 2005; Pang et al., 2007). Light annuli hyperpolarize $\mathrm{HCs}$ and $\mathrm{AC}_{\mathrm{OFF}} \mathrm{s}$ and decrease inhibitory neurotransmitter release from these cells to DBCs. Because chloride equilibrium potentials $\left(\mathrm{E}_{\mathrm{Cl}}\right)$ in DBCs have been found to be more positive than the dark membrane potential (Miller and Dacheux, 1983; Vardi et al., 2000), the annulus-induced decrease of inhibitory neurotransmitter results in closure of chloride channels (resistance increase) and hyperpolarizing surround responses in DBCs.

The third implication is that in addition to the HC-cone-HBC feedback pathway, the $\mathrm{ON}$ amacrine cell $\left(\mathrm{AC}_{\mathrm{ON}}\right)$ - $\mathrm{HBC}$ feedback synapses (Fig. 4, pathway V) may contribute to $\mathrm{HBC}$ surround responses. Light annuli depolarize $\mathrm{AC}_{\mathrm{ON}} \mathrm{s}$ and increase inhibitory neurotransmitter release from these cells to HBC axon terminals. Because chloride in HBCs has been shown to be passively distributed (Miller and Dacheux, 1983) and center light spots hyperpolarize the $\mathrm{HBC}$ from its dark potential (and $\mathrm{E}_{\mathrm{Cl}}$ ), the annulus-induced inhibitory neurotransmitter release from $\mathrm{AC}_{\mathrm{ON}}$ s opens chloride channels (resistance decrease) in $\mathrm{HBCs}$ and result in a depolarizing surround response. On the other hand, $\mathrm{HC} \rightarrow \mathrm{HBC}$ feedforward chemical synapses should have minor (if any) contribution to HBC surround responses, because all $\mathrm{HCs}$ in the salamander retina hyperpolarize to light (Yang and Wu, 1989), and thus light annuli suppress HC neurotransmitter release, resulting in a resistance increase in HBCs.

In addition to pathways I, II, and V, results described by Figure 3 support the idea that $\mathrm{HC}-\mathrm{DBC}_{\mathrm{C}}$ electrical synapses contribute to $\mathrm{DBC}_{\mathrm{C}}$ surround responses (Fig. 4, pathway III): light an- 
nuli hyperpolarize the HCs, drawing current from $\mathrm{DBC}_{\mathrm{C}} \mathrm{s}$ via the gap junction channels (without resulting in resistance changes) and hyperpolarize the $\mathrm{DBC}_{\mathrm{C}} \mathrm{s}$. This is consistent with the dye coupling data shown in Figure $1 a$ and in our previous $\mathrm{HC}$ study $\left[\mathrm{DBC}_{\mathrm{C}} \mathrm{s}\right.$ are dye coupled with wide-field $\mathrm{HCs}$ (type B HC somas and axon terminals)] (Zhang et al., 2006).

\section{Discussion}

$\mathrm{BC}$ receptive center size varies with relative rod/cone inputs and degree of BC-BC coupling

Results described in this article suggest that the center and surround responses of various types of $\mathrm{BCs}$ in the tiger salamander retina are mediated by heterogeneous synaptic circuitry. The BC receptive field center diameters (RFCD) vary with the relative rod/cone input $(\Delta \mathrm{S})$ : RFCD is larger in DBCs with stronger cone input, and it is larger in HBCs with stronger rod input (Table 1). RFCD also correlates with the degree of dye coupling: $\mathrm{BCs}$ with larger RFCD are more strongly dye coupled with neighboring cells of the same type, suggesting that $\mathrm{BC}-\mathrm{BC}$ coupling significantly contributes to the $\mathrm{BC}$ receptive field center.

Membrane resistance measurements show that the center voltage responses of all HBCs are associated with a resistance increase and those of all DBCs are accompanied with a resistance decrease (Table 2 ). This is consistent with the notion that glutamate released from rods and cones in darkness opens AMPA receptor-mediated cation channels in HBCs and closes mGluR6 receptor-mediated cation channels in DBCs (Slaughter and Miller, 1981; Maple et al., 1999). Center light stimuli hyperpolarize rods and cones, suppress glutamate release, and result in a resistance increase (close ion channels) in $\mathrm{HBCs}$ and a resistance decrease (open ion channels) in DBCs. There is no significant difference in resistance changes among BCs with different $\mathrm{rod} /$ cone inputs, indicating that rod and cone output synapses cause similar postsynaptic conductance changes in BCs.

Heterogeneous BC surround synaptic pathways and ON/OFF crossover lateral inhibition

In Figure 4, we illustrate the possible and unlikely synaptic pathways underlying surround inputs of various types of BCs. Our results suggest that the $\mathrm{HC}$ cone-BC feedback synapses contribute to the surround responses of all 6 type of BCs. The negative HC-cone feedback a

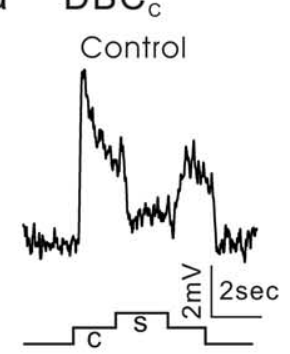

LAP4

Wash
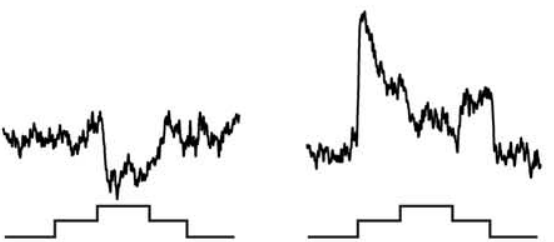

b $\mathrm{DBC}_{\mathrm{c}}$

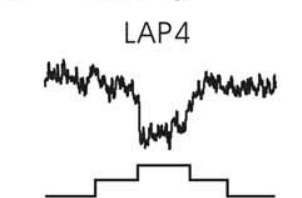

LAP4 + MFA

LAP4
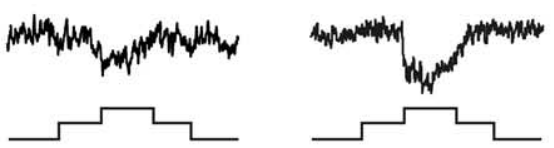

c $\mathrm{HC}$
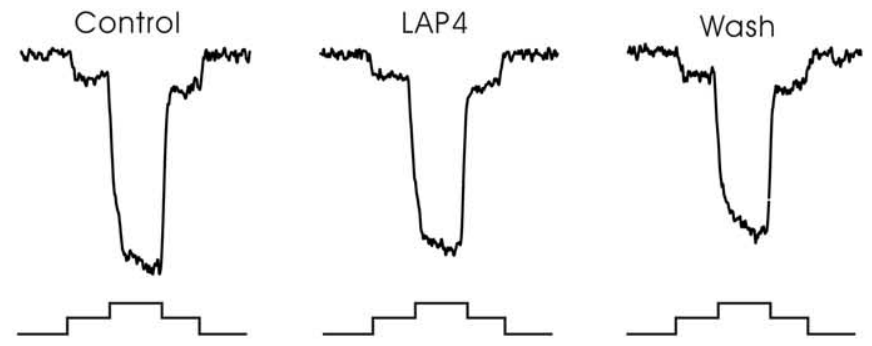

d $\mathrm{HC}$
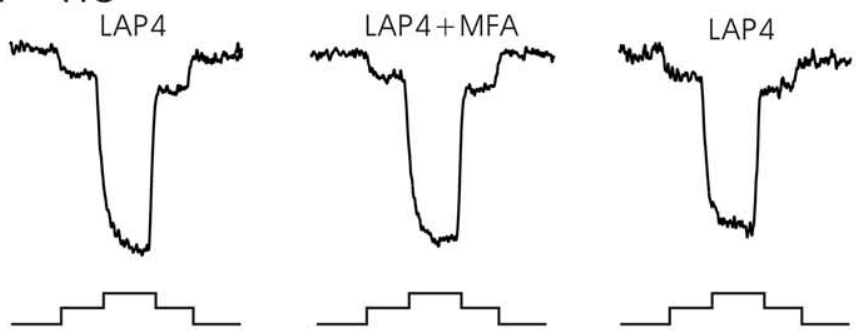

e

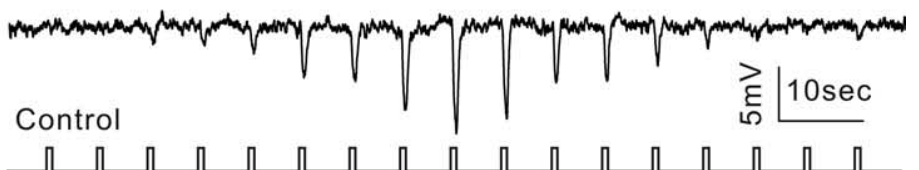

Step of $120 \mu \mathrm{m}$, receptive field $1,340 \mu \mathrm{m}$
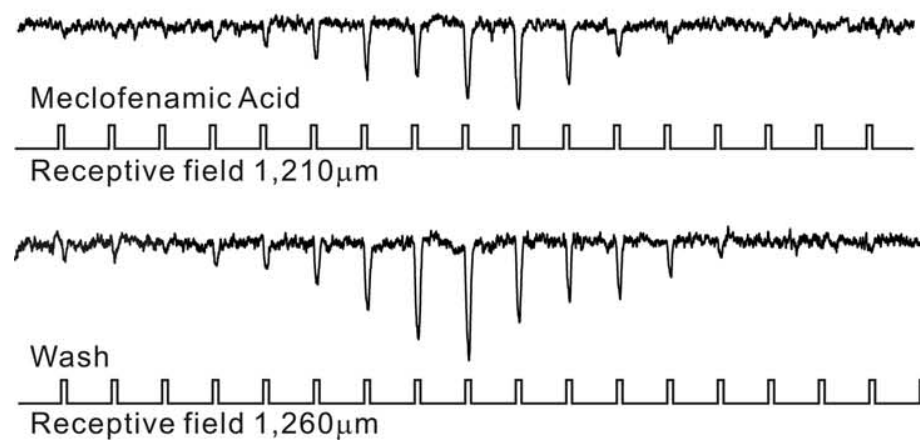

Figure 3. $\quad \boldsymbol{a}$, Effects of $50 \mu \mathrm{mL}-\mathrm{AP} 4$ on center ( $500 \mu \mathrm{m}$ light spot) and surround (annulus, $700 \mu$ m inner diameter and $2000 \mu \mathrm{m}$ outer diameter) responses of a DBC C.L-AP4 selectively abolished the center response and slightly reduced the surround response. $\boldsymbol{b}$, The residual surround response was blocked by $100 \mu \mathrm{MMFA}$, suggesting that the surround response is mediated by the HC-DBC electrical synapse.c-e, A $150 \mu \mathrm{M}$ MFA did not affect HCs center and surround responses $(\boldsymbol{c}, \boldsymbol{d})$ and receptive field size $(\boldsymbol{e})$. 
A.
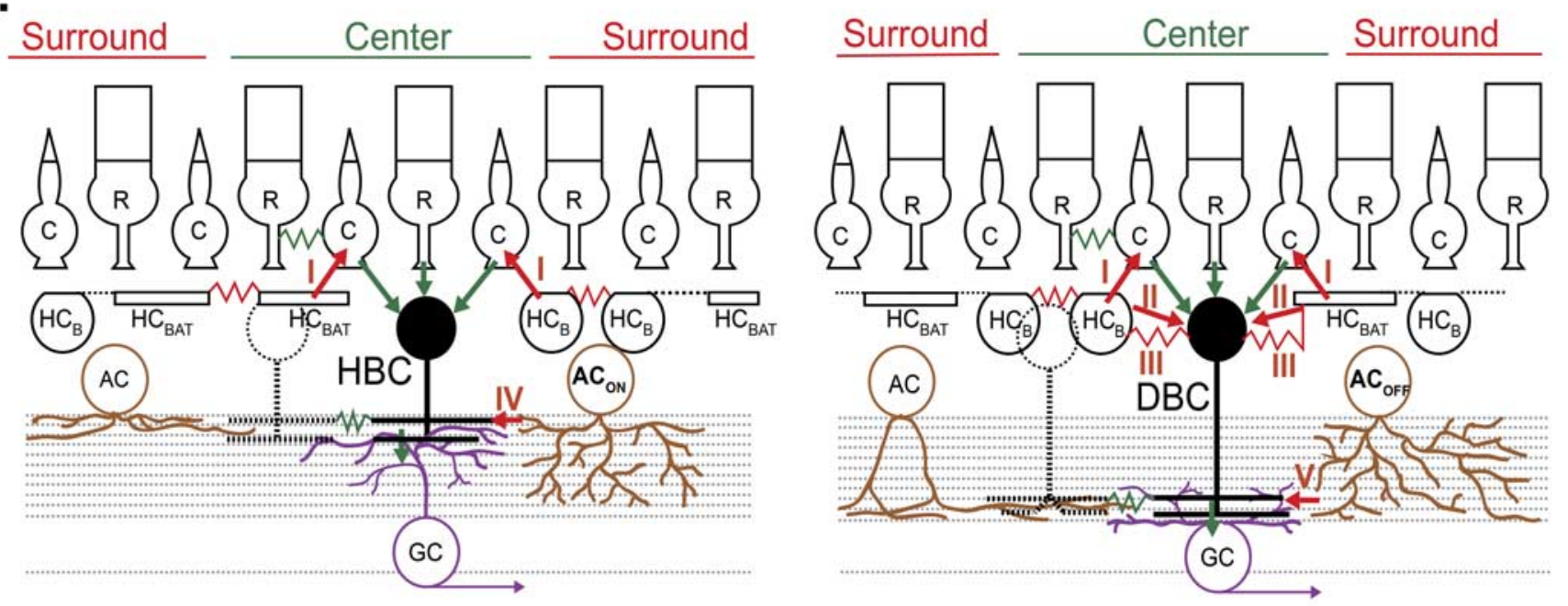

B.

\begin{tabular}{|c|c|c|c|c|c|c|c|}
\hline & \multicolumn{2}{|c|}{$\begin{array}{c}\text { Center Synaptic } \\
\text { Organization }\end{array}$} & \multicolumn{5}{|c|}{ Surround Synaptic Pathways } \\
\hline & $\begin{array}{l}\text { rod/cone } \\
\text { inputs }\end{array}$ & $\begin{array}{l}\mathrm{BC}-\mathrm{BC} \\
\text { coupling }\end{array}$ & $\begin{array}{l}\mathrm{HC} \text { feedback (I) } \\
\mathrm{HC} \rightarrow \text { cone } \rightarrow \mathrm{BC}\end{array}$ & $\begin{array}{l}\text { HC feedforv } \\
\text { (II) chemica }\end{array}$ & $\begin{array}{l}\mathrm{HC} \rightarrow \mathrm{BC} \\
\text { l) electrical }\end{array}$ & $\begin{array}{l}\mathrm{AC} \text { feedbac } \\
\left(\text { IV) } \mathrm{AC}_{\mathrm{ON}} \rightarrow \mathrm{B}\right.\end{array}$ & (l) $\mathrm{AC}_{\mathrm{OFF}} \rightarrow \mathrm{BC}$ \\
\hline $\mathrm{HBC}_{\mathrm{R}}$ & $\begin{array}{l}\text { Rod: +++ } \\
\text { Cone: + }\end{array}$ & +++ & 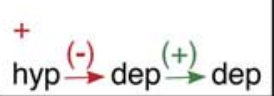 & no & no & $\begin{array}{l}\text { yes } \\
\operatorname{dep} \stackrel{(+)}{\rightarrow} \text { dep }\end{array}$ & \\
\hline $\mathrm{HBC}_{\mathrm{M}}$ & $\begin{array}{l}\text { Rod: ++ } \\
\text { Cone: ++ }\end{array}$ & ++ & $\stackrel{++}{\text { hyp }} \stackrel{(-)}{\rightarrow}$ dep $\stackrel{(+)}{\rightarrow}$ dep & no & no & $\begin{array}{l}\text { yes } \\
\operatorname{dep} \stackrel{(+)}{\rightarrow} \text { dep }\end{array}$ & \\
\hline $\mathrm{HBC}_{\mathrm{c}}$ & $\begin{array}{l}\text { Rod }+ \\
\text { Cone +++ }\end{array}$ & ++ & $\stackrel{+++}{\operatorname{hyp}} \stackrel{(-)}{\rightarrow} \operatorname{dep} \stackrel{(+)}{\rightarrow}$ dep & no & no & $\begin{array}{l}\text { yes } \\
\operatorname{dep} \stackrel{(+)}{\rightarrow} \text { dep }\end{array}$ & no \\
\hline $\mathrm{DBC}_{\mathrm{c}}$ & $\begin{array}{l}\text { Rod: + } \\
\text { Cone: +++ }\end{array}$ & + & hyp $\stackrel{(-)}{\rightarrow}$ dep $\stackrel{(-)}{\rightarrow}$ hyp & $\begin{array}{l}\text { yes } \\
\text { hyp } \stackrel{(+)}{\rightarrow} \text { hyp }\end{array}$ & hyp $\stackrel{(+)}{\rightarrow}$ hyp & no & $\begin{array}{l}\text { yes } \\
\text { hyp } \stackrel{(+)}{\rightarrow} \text { hyp }\end{array}$ \\
\hline $\mathrm{DBC}_{\mathrm{M}}$ & $\begin{array}{l}\text { Rod: ++ } \\
\text { Cone: }++\end{array}$ & + & $\stackrel{++}{\text { hyp } \stackrel{(-)}{\rightarrow} \text { dep } \stackrel{(-)}{\rightarrow} \text { hyp }}$ & $\begin{array}{l}\text { yes } \\
\text { hyp } \stackrel{(+)}{\rightarrow} \text { hyp }\end{array}$ & & no & $\begin{array}{l}\text { yes } \\
\text { hyp } \stackrel{(+)}{\rightarrow} \text { hyp }\end{array}$ \\
\hline $\mathrm{DBC}_{\mathrm{R}}$ & $\begin{array}{l}\text { Rod: +++ } \\
\text { Cone: + }\end{array}$ & 0 & 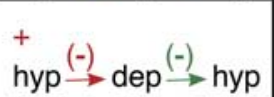 & $\begin{array}{l}\text { yes } \\
\text { hyp } \stackrel{(+)}{\rightarrow} \text { hyp }\end{array}$ & & no & $\begin{array}{l}\text { yes } \\
\text { hyp } \stackrel{(+)}{\rightarrow} \text { hyp }\end{array}$ \\
\hline
\end{tabular}

Figure 4. Center-surround antagonistic receptive field organization of bipolar cells. $A$, Schematic diagrams of center (green) and surround (red) synaptic pathways of HBCs (left) and DBCS (right). $\mathrm{R}$, rod; $\mathrm{C}$, cone; $\mathrm{HC}_{\mathrm{B}}$, $\mathrm{B}$-type $\mathrm{HC}$ somas; $\mathrm{HC}_{\mathrm{BAT}}$, B-type $\mathrm{HC}$ axon terminals; arrows, chemical synapses; zig-zags, electrical synapses; $\mathrm{I}-\mathrm{V}$, five surround synaptic pathways list in $\boldsymbol{B}$. $\boldsymbol{B}$, Variations in synaptic pathways mediating center (green) and surround (red) responses of the $\mathrm{HBC}_{R} \mathrm{~S}, \mathrm{HBC}_{\mathrm{M}} \mathrm{s}, \mathrm{HBC} \mathrm{C}_{\mathrm{S}}, \mathrm{DBC}_{C} \mathrm{~s}, \mathrm{DBC}_{\mathrm{M}} \mathrm{s}$, and $\mathrm{DBC}_{\mathrm{R}} \mathrm{s}$. +++ , strong; ++ , intermediate; + , moderate; yes, possible; no, unlikely. For the possible pathways, response polarities (hyp, hyperpolarization; dep, depolarization) in each neuron and the synaptic sign $[(+)$, sign-preserving; or $(-)$, sign-inverting] in each synapse in the pathways are indicated [e.g., in the $\mathrm{HBC}_{\mathrm{R}} \mathrm{HC} \rightarrow$ cone $\rightarrow \mathrm{BC}$ pathway: (hyperpolarization in $\mathrm{HC}$ ) via a sign-inverting synapse $\rightarrow$ (depolarization in cone) via a sign-preserving synapse $\rightarrow$ (depolarization in $\mathrm{BC})$ ].

synapses (pathway I) partially "turn off” the center responses by depolarizing the cones (Baylor et al., 1971; Skrzypek and Werblin, 1983), because the membrane resistance changes associated with surround responses of all BCs are opposite to the resistance changes associated with center responses (Fig. 1e, Table 2).

Although all BCs sharing a common surround response pathway (the $\mathrm{HC}$-cone-BC feedback pathway), various types of BCs use different $\mathrm{HC}$ and $\mathrm{AC}$ inputs to mediate their surround responses. It is unlikely, for example, that HBC surround responses are directly mediated by chemical synaptic inputs from hyperpolarizing lateral neurons such as $\mathrm{HCs}$ and $\mathrm{AC}_{\mathrm{OFF}} \mathrm{s}$ because of resistance change mismatch, and thus $\mathrm{HBCs}$ may only receive surround inputs from $\mathrm{HC}$-cone-HBC and $\mathrm{AC}_{\mathrm{ON}}-\mathrm{HBC}$ synapses. On the other hand, resistance analysis suggests that DBC surround responses can be mediated by $\mathrm{HC}$-cone-DBC, $\mathrm{HC}-\mathrm{DBC}$, and $\mathrm{AC}_{\mathrm{OFF}}-\mathrm{DBC}$ chemical synapses, but not the $\mathrm{AC}_{\mathrm{ON}}-\mathrm{DBC}$ synapses. Moreover, dye coupling and MFA results indicate that $\mathrm{DBC}_{\mathrm{C}} \mathrm{s}$ receive additional surround inputs from wide-type HCs through electrical synapses. Despite the heterogeneity, it is interesting to point out that a ON/OFF crossover inhibition rule applies here: cells with OFF (hyperpolarizing) responses ( $\mathrm{HCs}$ and $\mathrm{AC}_{\mathrm{OFF}} \mathrm{s}$ ) mediate surround inhibitory inputs to $\mathrm{ON}$ cells (DBCs); and cells with $\mathrm{ON}$ (depolarizing) responses $\left(\mathrm{AC}_{\mathrm{ON}} \mathrm{s}\right)$ mediate surround inhibitory inputs to OFF cells (HBCs). ON/OFF crossover inhibition from amacrine cells to ganglion cells have been reported in the salamander and mammalian retinas (Pang et al., 2007; Hsueh et al., 2008), and our data here suggest that it may be a general rule for lateral inhibition in the visual system. 


\section{Heterogeneous receptive field organizations in the visual system}

Synaptic pathways mediating center and surround responses of various types of BCs are summarized in Figure 4. Synaptic inputs mediating center responses are analyzed based on our measurements of $\Delta S$ values, degree of dye coupling and receptive field center diameters. DBCs and HBCs with different rod/cone inputs have different receptive field center diameters that closely correlate with the degree of homologous dye coupling (coupling with cells of the same type). This suggests that the center response of a given $\mathrm{BC}$ is not only mediated by direct photoreceptor inputs, but also by signal spreading from adjacent BCs. It also explains why the receptive field center diameters of BCs are generally larger than their dendritic field diameters (Borges and Wilson, 1987; Hare and Owen, 1990) and why different types of BCs exhibit different receptive field center sizes despite that their dendritic fields are of similar diameters (Wu et al., 2000).

Pathways for surround responses are derived from results on resistance changes associated with the surround responses and chloride equilibrium potential measurements from previous studies (Miller and Dacheux, 1983; Vardi et al., 2000), as well as patterns of dye coupling with HCs and actions of MFA on DBC surround responses. Although the resistance measurements and chloride equilibrium potentials provide qualitative supports for possible surround pathways for each type of BCs (Fig. 4), they cannot render a quantitative description on how much each surround pathway contribute to the surround responses of these BCs. Moreover, our analysis is unable to label the synapses mediating the surround responses of each type of BCs with exact neurotransmitter or presynaptic neuronal signatures. This is because we do not have synapse-specific pharmacological tools. For example, GABA may be involved in three of the possible pathways mediating $\mathrm{BC}$ surround responses (HC-cone feedback, HC-BC feedforward chemical, and AC-BC feedback synapses) (Wu, 1986; Wu, 1991; Lukasiewicz et al., 1994), and thus one cannot conclude which of the three synapses are involved in a given $\mathrm{BC}$ by blocking surround responses with GABA receptor antagonists. Nevertheless, our analysis in this article narrows down the likely (and unlikely) synaptic pathways responsible for surround responses of various types of BCs, as illustrated in Figure 4.

Previous anatomical and physiological studies have suggested that many of the aforementioned synaptic pathways (except for the $\mathrm{HC}-\mathrm{DBC}_{\mathrm{C}}$ electrical synapses) subserve center and surround inputs to BCs (Werblin and Dowling, 1969; Naka, 1972; Lukasiewicz et al., 1994; Ichinose and Lukasiewicz, 2005), and the underlying assumption has always been that these pathways are equally applicable to all BCs (Dowling, 1987; Wu, 1994). Results described here fundamentally challenge this assumption by showing that many of these pathways subserve receptive fields of certain types of BCs but not others. The concept of heterogeneous receptive field circuitry is not only applicable to salamander BCs, but also to BCs in other species and higher-order visual neurons. It has been shown, for example, that rod bipolar cells in the rabbit retina do not exhibit surround responses whereas cone BCs do (Bloomfield and Xin, 2000). Moreover, a recent study in the mammalian retina showed that ON ACs predominantly inhibit HBCs and $\mathrm{GC}_{\mathrm{OFF}} \mathrm{s}$, and OFF ACs mainly inhibit DBCs and $\mathrm{GC}_{\mathrm{ON}} \mathrm{s}$ (similar to pathways IV and V in this study) (Hsueh et al., 2008). All these results are consistent with the concept of heterogeneous surround synaptic circuitry set forth by the present study.

A major advantage of heterogeneous receptive field circuitry is that the center and surround responses of different types of BCs can be differentially modulated. For example, under the influence of gap junction regulators (e.g., dopamine, which is released from some amacrine cells in flicker light) (Weiler et al., 1997), receptive fields of $\mathrm{HBC}_{\mathrm{R}} \mathrm{s}$ may be decreased where those of the $D_{B C} s$ will remain the same, because of the differences in the RFCD and dye coupling between these two types of BCs (Figs. 1, 2). Consequently, spatial tuning of the rod-OFF channel could be sharpened in flicker lights where that of the rod-ON channel is not. Moreover, because steady background light tonically hyperpolarizes HCs, but not the transient Acs (Yang and Wu, 1989; Pang et al., 2007), constant background illumination may reduce the DBC surround responses more than the HBC surround responses. This is because $\mathrm{HC}-\mathrm{DBC}$ chemical synapses mediates $\mathrm{DBC}$ surround responses (and $\mathrm{HC}-\mathrm{DBC}_{\mathrm{C}}$ electrical synapses contribute to the $\mathrm{DBC}_{\mathrm{C}}$ surround responses), and $\mathrm{HC}-\mathrm{HBC}$ chemical synapses do not mediate HBC surround responses. Therefore in the presence of steady adapting illumination, contrast sensitivity of the ON channels should be more markedly augmented than that of the OFF channels. It is possible that such differential modulation of receptive fields is not limited to retinal BCs, but also applicable for other visual neurons to compute spatial and contrast information under different lighting and adaptation conditions.

\section{References}

Baylor DA, Fuortes MG, O’Bryan PM (1971) Receptive fields of cones in the retina of the turtle. J Physiol 214:265-294.

Bloomfield SA, Xin D (1997) A comparison of receptive-field and tracercoupling size of amacrine and ganglion cells in the rabbit retina. Vis Neurosci 14:1153-1165.

Bloomfield SA, Xin D (2000) Surround inhibition of mammalian AII amacrine cells is generated in the proximal retina. J Physiol 523:771-783.

Borges S, Wilson M (1987) Structure of the receptive fields of bipolar cells in the salamander retina. J Neurophysiol 58:1275-1291.

Dowling JE (1987) The retina, an approachable part of the brain. Cambridge, MA: Harvard University Press.

Hare WA, Owen WG (1990) Spatial organization of the bipolar cell's receptive field in the retina of the tiger salamander. J Physiol 421:223-245.

Hsueh HA, Molnar A, Werblin FS (2008) Amacrine to amacrine cell inhibition in the rabbit retina. J Neurophysiol 100:2077-2088.

Hubel DH, Wiesel TN (1962) Receptive field, binocular interaction and functional architecture in the cat's visual cortex. J Physiol 160:106-154.

Ichinose T, Lukasiewicz PD (2005) Inner and outer retinal pathways both contribute to surround inhibition of salamander ganglion cells. J Physiol 565:517-535.

Kamermans M, Fahrenfort I, Schultz K, Janssen-Bienhold U, Sjoerdsma T, Weiler R (2001) Hemichannel-mediated inhibition in outer retina. Science 292:1178-1180.

Lukasiewicz PD, Maple BR, Werblin FS (1994) A novel GABA receptor on bipolar cell terminals in the tiger salamander retina. J Neurosci 14:1202-1212.

Maple B, Zhang J, Pang JJ, Gao F, Wu SM (2004) Characterization of displaced bipolar cells in the tiger salamander retina. Vision Res 44:650-658.

Maple BR, Gao F, Wu SM (1999) Glutamate receptors differ in rod- and cone-dominated off-center bipolar cells. Neuroreport 10:3605-3610.

Miller RF, Dacheux RF (1983) Intracellular chloride in retinal neurons: measurement and meaning. Vision Res 23:399-411.

Naka KI (1972) The horizontal cells. Vision Res 12:573-588.

Pan F, Mills SL, Massey SC (2007) Screening of gap junction antagonists on dye coupling in the rabbit retina. Vis Neurosci 24:609-618.

Pang JJ, Gao F, Wu SM (2004) Stratum-by-stratum projection of light response attributes by retinal bipolar cells of Ambystoma. J Physiol 558:249-262.

Pang JJ, Gao F, Wu SM (2007) Cross-talk between ON and OFF channels in the salamander retina: indirect bipolar cell inputs to ON-OFF ganglion cells. Vision Res 47:384-392.

Skrzypek J, Werblin F (1983) Lateral interactions in absence of feedback to cones. J Neurophysiol 49:1007-1016. 
Slaughter MM, Miller RF (1981) 2-Amino-4-phosphonobutyric acid: a new pharmacological tool for retina research. Science 211:182-185.

Vardi N, Zhang LL, Payne JA, Sterling P (2000) Evidence that different cation chloride cotransporters in retinal neurons allow opposite responses to GABA. J Neurosci 20:7657-7663.

Verweij J, Hornstein EP, Schnapf JL (2003) Surround antagonism in macaque cone photoreceptors. J Neurosci 23:1049-1057.

Wassle H (2004) Parallel processing in the mammalian retina. Nat Rev Neurosci 5:747-757.

Weiler R, Baldridge WH, Mangel SC, Dowling JE (1997) Modulation of endogenous dopamine release in the fish retina by light and prolonged darkness. Vis Neurosci 14:351-356.

Werblin FS, Dowling JE (1969) Organization of the retina of the mudpuppy, Necturus maculosus. II. Intracellular recording. J Neurophysiol 32:339-355.

Wu SM (1986) Effects of gamma-aminobutyric acid on cones and bipolar cells of the tiger salamander retina. Brain Res 365:70-77.
Wu SM (1991) Input-output relations of the feedback synapse between horizontal cells and cones in the tiger salamander retina. J Neurophysiol 65:1197-1206.

Wu SM (1992) Feedback connections and operation of the outer plexiform layer of the retina. Curr Opin Neurobiol 2:462-468.

Wu SM (1994) Synaptic transmission in the outer retina. Annu Rev Physiol 56:141-168.

Wu SM, Gao F, Maple BR (2000) Functional architecture of synapses in the inner retina: segregation of visual signals by stratification of bipolar cell axon terminals. J Neurosci 20:4462-4470.

Yang XL, Wu SM (1989) Effects of background illumination on the horizontal cell responses in the tiger salamander retina. J Neurosci 9:815-827.

Yang XL, Wu SM (1990) Synaptic inputs from rods and cones to horizontal cells in the tiger salamander retina. Sci China B 33:946-954.

Zhang AJ, Zhang J, Wu SM (2006) Electrical coupling, receptive fields, and relative rod/cone inputs of horizontal cells in the tiger salamander retina. J Comp Neurol 499:422-431. 